\title{
O SOFRIMENTO PSIQUUICO DOS ENFERMEIROS QUE LIDAM COM PACIENTES ONCOLÓGICOS
}

\author{
THE MENTAL SUFFERING OF NURSES WHO DEAL. WITH ONCOLOGICAL PATIENTS \\ EL SUFRIMIENTO PSIQUUICO DE LOS ENFERMEROS QUE TRATAN COM PACIENTES \\ ONCOLÓGICOS
}

\author{
Juliana Bastoni da Silva ${ }^{1}$ \\ Débora Isane Ratner Kirschbaum ${ }^{2}$
}

\begin{abstract}
RESUMO: A fim de identificar as situaçōes enfrentadas pelos enfermeiros, que mais lhes desencadeiam sofrimento psíquico no cotidiano com paciente oncológico, e verificar as formas encontradas por estes profissionais para lidar com tal sofrimento, foram entrevistados quatro enfermeiros de um hospital-escola da cidade de Campinas, estado de São Paulo, que trabalhavam com pacientes oncológicos. A abordagem etnográfica foi empregada para realizar a coleta de dados. A entrevista não-diretiva, associada com observação de campo, foi a técnica utilizada para esta coleta. Para a análise dos dados, foi empregado como referencial metodológico a Análise do Conteúdo. Os resultados mostraram que muitas situaçōes do relacionamento enfermeiro-paciente oncológico suscitam sofrimento psíquico neste profissional. Estas situaçōes estão ligadas ao trabalho dos enfermeiros, ao tipo de paciente cuidado por estes profissionais e ao tipo de doença que apresenta o paciente. O presente estudo mostrou que. muitas vezes, os enfermeiros usam mecanismos de defesa contra esse sofrimento psíquico. A intençāo do trabalho é contribuir para o conhecimento do assunto e assim servir de base para a elaboração de medidas que possam amenizar problemas dessa natureza, que ocorrem, com os enfermeiros, que atuam na Área de Oncologia. Com este estudo. espera-se poder contribuir para a compreensão do desafio que é o câncer, doença que amedronta profissionais e a populaçāo em geral.
\end{abstract}

UNITERMOS: Sofrimento psíquico - Enfermeiros - Paciente oncológico.

ABSTRACT: In this qualitative study, four nurses of a teaching hospital in the city of Campinas, São Paulo-Brazil, all of them working with oncological patients were interviewed in order to verify the situation that most caused mental suffering in the day by day with these patients. Data collection were performed as proposed by the ethnografic approach and the non-directive interview and the direct observation was employed. The cointaint analysis has been utilized to the data analysis. The results have shown that many situations of the relationship nurses-oncological patients cause mental suffering in that professional. Those situations are tied to the work of the nurses, to the kind of patient treated by those professionals and to the kind of sickness presented by the patient. That study has shown that, many times, the nurses utilize defense mechanisms against that mental suffering. This work aims to contribute to the knowledge of the subject and therefore be itself a base in which one could elaborate mesures that can make these problems that occur with the nurses that work in the Oncology area lighter. With that study to contribute to the compreension of the challange that the cancer. sickness that make professional and population frighted, is.

KEYWORDS: Mental suffering - Nurses - Oncological patients.

\footnotetext{
${ }^{1}$ Aluna do sexto semestre do Curso de Graduação em Enfermagem -FCM / UNICAMP. Bolsista-Pesquisa do Serviço de Apoio ao Estudante da UNICAMP

${ }^{2}$ Enfermeira. Doutora em Saúde Mental, Professor Assistente Doutorado Departamento de Enfermagem -FCM/UNICAMP
}

R. Bras. Enferm. Brasília, v. 51, n. 2, p. 273-290, abr./jun., 1998 
RESUMEN: A fin de identificar las situaciones enfrentadas por los enfermeros, lo que más les desencadenan sufrimiento psíquico en el día a dia con paciente oncológico y verificar las formas encontradas por estes profesionales para tratar con tal sufrimiento, fueron entrevistados cuatro enfermeros de un hospital escuela de la ciudad de Campinas, Estado de São Paulo, que trabajaban con pacientes oncológicos. El abordaje etnográfico fué usado para realizar la colecta de datos. Para el análisis de los datos, fué usado como referencial metodológico el análisis del contenido. Los resultados mostraron que muchas situaciones del relacionamiento enfermero-paciente oncológico suscitan sufrimiento psíquico en este profesional. Estas situaciones están ligadas al trabajo de los enfermeros, al tipo de paciente cuidado por estes profesionales y al tipo de enfermedad que presenta el paciente. El presente estudio mostró que, muchas veces, los enfermeros usan mecanismos de defensa contra esse sufrimiento psíquico. La intención del trabajo es contribuir para el conocimiento del asunto y asi servir de base para la confección de medidas que puedan diminuir problemas de esa naturaleza, se espera poder contribuir para la comprensión del desafio que es el cáncer, enfermedad que atemoriza profesionales y a la población en general.

UNITÉRMINOS: Sufrimiento psíquico - Enfermero - Paciente oncológico.

\section{INTRODUÇÃO}

A presente pesquisa teve por objetivo identificar as situações enfrentadas pelos enfermeiros de um serviço de oncologia de um hospital-escola paulista, que mais Ihes desencadeiam sofrimento psiquico, assim como analisar as formas encontradas por estes profissionais para lidar com tais situações.

A importância dessa investigação reside no fato de que são escassos os estudos de caso existentes na literatura que abordam especificamente o sofrimento psiquico presente no trabalho de enfermeiros junto a pacientes oncológicos. Além disso, ela visa mostrar quais são as situações concretas que mais causam sofrimento psiquico no enfermeiro, procurando, assim, que as instâncias responsáveis pela coordenação e gerenciamento do pessoal de enfermagem possam adotar estratégias mais apropriadas para atenuar tais problemas.

Observa-se que os enfermeiros que trabalham em Oncologia possuem medos e inseguranças na assistência ao paciente com câncer, devido, geralmente, à desinformação em relação à doença em si e às formas de tratamento, bem como em decorrência das fantasias que se formam em torno do paciente causadas justamente pela falta de conhecimento (Ferreira, 1994).Os cursos de Graduação em Enfermagem não apresentam em seu curriculo uma disciplina especifica de Oncologia, o que é um outro problema para o enfermeiro.

Boemer e Valle (1988) apud Françoso (1993), que estudaram a Enfermagem na lida com o câncer infantil, apontam esse trabalho como dificil no 
que se refere ao tratamento físico e ao relacionamento com a familia do doente. Apontam também o desgaste emocional por que passam os profissionais dessa área, da carência de maior preparo nesse Setor de Oncologia. Segundo os autores, é um trabalho fonte de inquietação e questionamentos. Enfim, o desgaste pelo qual o enfermeiro passa é devido à exigência em nivel de relacionamento com o paciente e sua familia, além da exigência em nivel técnico do trabalho.

De acordo com Cassorla (1983), mesmo com altas porcentagens de cura e as sobrevidas cada vez mais longas para o doente, o profissional de saúde e o paciente oncológico passam por fases dificeis: a expectativa do diagnóstico, os tratamentos que implicam em amplas cirurgias, as reações de quimioterapia e da radioterapia e, principalmente, o longo tempo em que se vive à espera de uma recidiva ou à confirmação de uma cura. Ainda segundo o mesmo autor, o maior problema é a forma de comunicação na relação enfermeiro e/ou médico e paciente: o que falar, como falar e quando falar ao paciente. Estas dúvidas também geram um sofrimento psíquico no profissional que trabalha no Setor de Oncologia.

Além disso, determinados preconceitos a respeito da doença também são responsáveis por esse tipo de sofrimento experimentado pelo enfermeiro. Esses conceitos antecipados e algumas vezes sem fundamento razoável consistem na associação entre o câncer e os aspectos negativos, ameaçadores e temidos pela nossa cultura, como a dor, o sofrimento, a mutilação, a destruição e em última instância a morte (Françoso, 1993).

Cassorla (1983) aborda este aspecto assinalando que as fantasias em relação ao câncer são bem conhecidas: uma sensação consciente ou inconsciente de ser devorado, comido por dentro, destruido, e essas se articulam com as da morte. Segundo este autor, o câncer pode ser visto também como um castigo. Há a hipótese de que alguns pacientes desenvolvam o câncer também para se punirem, para purgarem suas culpas. O câncer, às vezes, é visto como uma doença sagrada, cujo nome não pode ser pronunciado.

Segundo Ferreira (1994), como forma de enfrentamento das situações consideradas dificeis pelos enfermeiros (e que lhes desencadeiam sofrimento psiquico), estes lançam mão de algumas técnicas de defesa socialmente constituidas, citadas por Menzies (1970). Trata-se principalmente das técnicas de evitação de envolvimento excessivo com o paciente. Uma destas técnicas é a procura do enfermeiro por manter sua "independência profissional" e busca de mudanças. Como mecanismos individuais de defesa foram mencionados pelos enfermeiros, entrevistados por Ferreira, a religião ou alguma forma de ajuda espiritual e inúmeros passatempos: passeios, execução de trabalhos manuais, leitura e meditação. A maioria mencionou o choro como válvula de escape. O estresse vivenciado pelos enfermeiros, aparentemente, se reflete numa variedade de sintomas, na grande maioria relacionados ao aparelho ósteo articular, ao aparelho digestivo e ao aparelho circulatório (Ferreira, 1994). A nosso ver, podem ter como causa a somatização física. 
De acordo com Françoso (1993), outra causa de sofrimento do enfermeiro é o intenso rodizio que existe entre profissionais do Setor de Oncologia. Este rodizio consiste na mudança de setor e com isso o enfermeiro sofre pela falta de gratificação pelo seu trabalho, uma vez que ele não vê a continuidade do mesmo.

No entanto, Françoso (1993) aponta um fato que contradiz o anterior. O enfermeiro é o profissional que permanece mais tempo ao lado do doente e da familia. Essa permanência e a proximidade decorrente dela geralmente é fonte de angústia e desgaste emocional.

Assim sendo, segundo esta autora, deve-se ponderar as duas situações e buscar uma atitude intermediária entre um envolvimento intenso com o paciente e uma separação brusca do mesmo. Procurando esse ponto de equilibrio na relação enfermeiro-paciente, busca-se também uma relação em que as necessidades do paciente sejam atendidas e o enfermeiro sinta-se um profissional apto para cumprir bem suas ações.

\section{PERCURSO METODOLÓGICO}

A atual pesquisa é exploratória, de natureza qualitativa, e tem como referencial teórico a psicopatologia do trabalho (Dejours, 1992).

A abordagem etnográfica foi empregada para realizar a coleta de dados. $A$ entrevista não-diretiva, associada com observação, foi a técnica utilizada para a coleta dos mesmos.

A entrevista não-diretiva evita as induções introduzidas pelo pesquisador e ultrapassa assim os niveis de resposta mais superficiais, atingindo as reações "mais profundas e mais verdadeiras" do sujeito interrogado (Thiollent, 1980). Essa entrevista é iniciada a partir de temas gerais ou ainda por perguntas abertas.

A observação de campo é usada como forma de complementar os dados obtidos através das entrevistas, pois, segundo Ludke, André (1986), nenhum método pode bastar-se a si mesmo numa pesquisa de natureza qualitativa.

No caso desta pesquisa, as entrevistas eram iniciadas a partir de perguntas abertas, cujos temas eram bem específicos (Anexo I).

A observação de campo foi realizada durante os estágios supervisionados de meu curso de Graduação em Enfermagem.

Os sujeitos entrevistados foram quatro. Em função do referencial teóricometodológico que foi adotado para análise dos dados coletados, optou-se por limitar o número de entrevistados, uma vez que, conforme explica Mynaio (1994, p.207), para a técnica que foi empregada "a qualidade da análise substitui a quantidade do material".

Para análise dos dados, foi empregado como referencial metodológico a Análise de Conteúdo (Bardin, 1979). 
Esta análise consiste na transcrição exaustiva de cada depoimento, conservando o máximo de informações lingüisticas (registro da totalidade dos significantes) e paralinguísticas (anotação de silêncios, pausas, lapsos, perturbações de palavras, aspectos emocionais como, por exemplo, risos, tom irônico, choro). As transcrições foram digitadas em espaço duplo, com margens à direita e à esquerda para facilitar anotações que se fizessem necessárias.

A transcrição de cada entrevista foi submetida a cuidadosa leitura, onde foram destacados os temas abordados por cada entrevistado. Após a classificação dos temas emergentes em cada depoimento, foram destacados os que apareciam com maior freqüência no discurso do conjunto dos entrevistados.

Retomando a idéia anterior, para alcançar os objetivos da pesquisa, foi realizado um estudo de caso com quatro enfermeiros, escolhidos de acordo com os seguintes critérios:

1. O enfermeiro deveria trabalhar no periodo diurno, devido a uma maior facilidade que o pesquisador teria para contactar com o sujeito:

2. Teria que atuar na assistência direta ao paciente, pois, segundo a literatura, este é um dos fatos que pode gerar sofrimento psíquico no enfermeiro;

3. Deveria ter disponibilidade pessoal para participar da pesquisa;

4. Ter concluido sua graduação há no minimo seis meses antes de ingressar na enfermaria;

5. Pertencer ao grupo de enfermeiros que há mais tempo atuava na enfermaria de oncologia.

Os últimos critérios foram adotados em função das conclusões de Pitta (1994) para quem o sofrimento psiquico dos enfermeiros inexperientes é maior do que o experimentado pelos enfermeiros mais experientes ao lidar com o paciente oncológico. Segundo observou em sua pesquisa, a mesma autora coloca que os enfermeiros com mais de 15 anos de profissão já aprenderam a lidar com o sofrimento psiquico e outras dificuldades que aparecem no dia-a-dia do hospital.

Em se tratando de aspectos éticos, pode-se dizer que as entrevistas foram gravadas, mediante autorização dos informantes, cuja identidade foi mantida em sigilo. Estes foram designados por números correspondentes a cada profissional entrevistado. As entrevistas duraram 17 minutos, em média.

Os sujeitos que preencheram os critérios citados anteriormente, excetuando o item 4, foram indicados pela Chefia de Enfermagem do Setor de Oncologia. Após tal indicação, as entrevistas foram realizadas através do agendamento com os sujeitos em horário e local estabelecidos de comum acordo entre estes e o pesquisador.

Todas as entrevistas foram realizadas no próprio local de trabalho desses enfermeiros (CAISM - Centro de Atençäo Integral à Saúde da Mulher - da 
UNICAMP) e também dentre o horário de trabalho dos mesmos, mediante autorização da enfermeira chefe do Setor de Oncologia.

Ainda sobre os sujeitos da pesquisa, pode-se dizer que todos atuavam no Serviço de Oncologia do CAISM, mas em áreas e cargos diferentes. Contudo, todos estavam ligados à assistência direta ao paciente. As quatro entrevistadas eram do sexo feminino, sendo que uma trabalhava em ambulatório e três em enfermaria de oncologia. Dentre os cargos exercidos, havia um de supervisão e outro de docência em Enfermagem. Três dentre as enfermeiras entrevistadas já trabalhavam há 10 anos em oncologia, sendo que uma delas interrompeu por três anos o seu trabalho como enfermeira. A outra entrevistada lidava com pacientes oncológicos há 30 anos.

\section{APRESENTAÇÄO E DISCUSSÃO DOS RESULTADOS}

\section{O cotidiano de trabalho segundo a visão dos enfermeiros}

Iniciando a entrevista, as enfermeiras foram interrogadas sobre o cotidiano que vivenciam com pacientes oncológicos. Dentre os vários aspectos levantados as entrevistadas ressaltam a complexidade da assistência que, além da parte técnica do trabalho, de certa forma, "exige" também um envolvimento profissional com o paciente. Uma das entrevistadas coloca que a parte administrativa do trabalho do enfermeiro dificulta um maior envolvimento com o paciente, que seria o ideal num tratamento, do ponto de vista dessa entrevistada.

"A nível de... de assistência é bastante complexo, né? Você tem bastante coisa para estar fazendo, para eu estar fazendo, é... muitas coisas para estar observando, sentimentos para estar trocando, é..., eu considero assim até difícil, tá?, para mim em relação a nível de envolvimento" (Entrevista 2).

"Ainda falta muito, né?, para eu chegar realmente àquilo que eu acho que é o ideal, por que eu ainda vejo muito a parte administrativa, principalmente agora como supervisora...

(Entrevista 2).

Segundo Carvalho \& Castro (1979) apud Silva (1986), as enfermeiras estão desempenhando funçöes administrativas e de supervisão, embora estas não sejam reconhecidas como especificas da categoria (num dado tempo e numa sociedade determinada). As enfermeiras brasileiras optaram por aquelas funções, e ao fazerem isto afastaram-se de seu objeto de trabalho (cuidado direto).

Outra enfermeira acrescenta que o seu cotidiano depende do seu estado emocional e também de resposta do paciente ao tratamento. É colocado também que o tipo de paciente exerce influência sobre o cotidiano dela. 
"O dia-a-dia depende muito de como você está emocionalmente naquele dia, tá?, e como que o paciente também responde, ahn, ao tratamento, se é um paciente mais agressivo, se é um paciente mais tranqüilo, se é um paciente que tá sofrendo muito, se é um paciente que é mais resignado a dor, se ele é mais revoltado com a doença" (Entrevista 1).

Um dos pontos levantados neste depoimento é que o tipo de paciente influencia no cotidiano da enfermeira. Segundo Ferreira (1994), fatos como a criação de vínculos do profissional com o paciente oncológico, o envolvimento emocional que permeia a relação enfermeiro-paciente, permitem que o profissional crie alguns mitos sobre o paciente (paciente bonzinho, paciente indefeso, ...). Esses mitos, de certa forma, influenciam o trabalho da enfermeira.

Entretanto, em um outro depoimento, nenhum dos temas levantados até então aparecem. A enfermeira apenas faz um relato de suas atividades, do seu periodo de trabalho e dos tipos de tratamento que existem no Ambulatório de Radioterapia onde trabalha. Pode-se levantar a hipótese de que essa enfermeira lida muito bem com as suas emoções e por isso ela não fala de problemas dessa ordem em seus relatos. Ou então essa enfermeira sofre na lida com o paciente oncológico, mas não falando desse sofrimento, negando-o, ela pode estar usando um mecanismo contra o sofrimento psíquico gerado pelo contato direto com esse tipo de paciente.

No estudo de Ferreira (1994), encontram-se depoimentos similares aos anteriores.

O grande número de funções que the são atribuidas pode funcionar também como um mecanismo social de defesa citado por Menzies (1970), contra a ansiedade e outras formas de sofrimento psíquico. Esse mecanismo de defesa é produzido pelas e nas instituições para evitar que o sujeito, no caso a enfermeira, entre em contato com seus conflitos.

Este mecanismo, denominado negação, possibilita ao enfermeiro negar a morte e é um dos mais simples e primitivos mecanismos de defesa. Segundo D'andrea (1996), consiste no bloqueio de certas percepções do mundo externo, ou seja, o individuo, frente a determinadas situações intoleráveis da realidade externa, inconscientemente nega sua existência para proteger-se do sofrimento.

No caso das enfermeiras que lidam com pacientes oncológicos, pode acontecer o seguinte: elas tentam negar a morte, mas de certa forma, este paciente, muitas vezes, Ihes mostram com o seu mau prognóstico que a morte realmente existe e não há como escapar dela.

\section{Lidando com o paciente oncológico}

Tal dificuldade de abordar a questão da morte confirma-se quando se trata das dificuldades que as entrevistadas identificam na sua relação profissional com o paciente oncológico. 
Em relação à visão que o enfermeiro tem do câncer, conforme depreende-se dos depoimentos, as enfermeiras entrevistadas, como a maioria dos profissionais de saúde que trabalham com pacientes oncológicos, possuem representações negativas sobre o câncer, associando-se à morte, tal como se vê a seguir:

"... a dificuldade eu acho que é identificada a partir do momento que você está lidando com a questão direta que é o morrer, né?" (Entrevista 1).

"... porque eu acho que a realidade, ahn, não somos preparados, tá?, para lidar com a morte, tá?, eu sou espírita mas eu até hoje não estou preparada para lidar com a morte" (Entrevista 2).

Ferreira (1994), através dos depoimentos coletados em sua pesquisa, confirma essa idéia de que as enfermeiras que trabalham com pacientes com câncer trazem consigo representações sobre a doença, que na maioria das vezes são negativas. No estudo dessa autora, uma das entrevistadas se refere ao câncer como sinônimo de morte.

Corroboram essa questão Ferraz et alii (1986) apud Germano (1993) ao afirmarem que os profissionais de saúde não estão preparados, a partir dos seus próprios sentimentos, para enfrentar as dificuldades diante da situação "morte".

Observa-se que, quando o câncer atinge uma pessoa conhecida pelas enfermeiras, as imagens negativas da doença, apresentadas por essas profissionais, são ainda mais expressivas:

"... se minha mãe tiver com câncer é... um sentimento assim de ... de muita dor, né? Eu olhar lá pro futuro e ver o que ela vai ter que passar se não for uma morte rápida, o sofrimento que ela vai ter" (Entrevista 1).

"Eu acho que a primeira coisa que me vem na cabeça é realmente, vem na cabeça e vem o sentimento de sentir pena dessa pessoa, tá? E essa coisa assim de que... ela vai morrer, dependendo realmente do nível e do estágio que tiver porque a gente não sabe, né?"( Entrevista 2).

Ferreira (1994) diz que a grande chance de cura do indivíduo, muitas vezes, decorre do diagnóstico precoce, o que raramente ocorre devido à falta de informação do próprio paciente, assim como pelo despreparo dos profissionais da área de saúde que o atendem.

Contudo, algumas enfermeiras têm uma visão diferente do câncer e não tão negativa como as anteriores, quando o câncer atinge uma pessoa conhecida do profissional de saúde, como se vê a seguir:

"Bom quando tem um conhecido, né?, que eu sei que está com câncer eu acho que primeiramente eu... eu tenho que estar conversando com ele, sobre o que ele pensa, o que ele sabe $e$ a primeiro... a primeira coisa que vem-me pela minha cabeça é de estar 
orientando, né?" "(...) é uma doença que qualquer pessoa pode ter, né?" "(...) câncer é uma palavra natural, né?" (Entrevista 3).

Outra enfermeira mostrou ter uma visão semelhante a essa imediatamente anterior, no que se refere à orientação do paciente.

"..., então eu geralmente, eu pergunto se o médico é bom, se eu o conheço, eu investigo a respeito, vejo se está sendo bem tratado..." "(...) converso, explico, explico os sintomas..., o que que ela está sentindo, porque que ela está sentindo..." "(...) Eu estou sempre pensando na prevenção, na questão da prevenção, alertando as pessoas para a prevenção e também sempre achando que ainda tem tal recurso, tem outro recurso, nunca liqüidando $e$, achando que $o$ câncer é sinônimo de morte" (Entrevista 4).

Tal como no estudo de Ferreira (1994), outras idéias presentes neste trabalho é a de que, dependendo da fase em que a doença é descoberta, o paciente tem sobrevida longa; a de que câncer é uma patologia como qualquer outra e outras enfermeiras apresentam umas visão mais amadurecida sobre a doença, demonstrando uma experiência concreta com a problemática do câncer e do seu tratamento.

A partir da reflexão que fizemos dos depoimentos, notamos que, para lidar com essa situação, o enfermeiro pode recorrer a mecanismos de defesa como a sublimação e a negaçäo. No primeiro caso, ele procura, por exemplo, construir uma "teoria" a respeito da morte para ajudar o paciente a entender que eventos como uma doença, mesmo grave como o câncer, fazem parte da vida, que todos estão sujeitos a ela e que existem formas de prevenção.

Segundo modo de lidar com a situação é negar a doença, naturalizando-a, ou seja, tratando-a como um fenômeno biológico. Ou seja, todos os seres humanos são iguais, todos são um conjunto de células e onde há célula pode haver reproduçäo anormal das mesmas; portanto, ninguém está livre disso. Essa posição oculta que o ser humano é um sujeito social e, por isso, vive mergulhado num mundo de cultura. Uma pessoa é um ser de cultura, logo, além do corpo físico, tem o vivido, o experimentado. Assim é diferente dos animais e das plantas que morrem e pronto, sem se perguntar para onde vão, porque morrem, se há vida depois da morte ou se haveria alternativa a ela. Os homens vivem procurando remédio para evitar a morte e para prolongar a vida. $O$ homem se preocupa com a morte e, para ele, ela não é como para os animais. Portanto, negar a morte enquanto um acontecimento significativo, cheio de significações, é o mesmo que dizer que o homem não é um ser social e reduzi-lo a um ser biológico. Para não ter que reconhecer esta situação de ser finito e mortal, as pessoas tendem a recorrer a explicaçōes reducionistas, biologizantes, alienadas, tentando mostrar ou convencer-se de que tais significações não existem. Dai a fala das enfermeiras, de que câncer é uma palavra natural, todo mundo pode ter.

Todas essas operações que as enfermeiras fazem para não se incomodar com a morte e com o câncer são possibilitadas pelos mecanismos de negação e de racionalização (D'andrea,1996), que é o que lhes permite não entrar em 
contato com o sentimento de impotência que elas experimentam diante do câncer.

Além da morte e do sofrimento, que já foram apontados como problema, outras dificuldades serão apontadas agora pelas entrevistadas na relação enfermeira/paciente e estão relacionadas à representação social da doença e às condições de vida do paciente oncológico.

O câncer é uma doença que tem uma repercussão em nivel cultural, social e econômico da vida do paciente, segundo uma enfermeira, e isso é apontado por ela como uma dificuldade que o paciente tem que enfrentar.

"As dificuldades que ele enfrenta é muito, né? Com a familia e com ele próprio, é com os filhos e esse envolvimento todo com o aspecto cultural, social, econômico que é um tratamento caro, né? (Entrevista 3).

Uma enfermeira relata uma outra dificuldade que os profissionais de saúde têm na lida com o paciente oncológico, a qual gera um tipo de sofrimento para o paciente.

"Quanto às dificuldades físicas, por exemplo, de lidar com o paciente oncologico ã... muitas vezes, é... o problema do paciente acamado e... muito difícil de lidar pelo peso deles e pelos recursos que nós temos a nível de Brasil, né?"

"... quando ele está numa fase mais difícil a gente acaba deixando ele muito na cama..."

"... então emocionalmente ele fica péssimo porque ele está sempre vendo o mesmo ambiente, né?" (Trechos retirados da entrevista 4). Essa dificuldade física (a obesidade do paciente que dificulta a sua manipulação) também foi mencionada no hospital em estudo por Ferreira (1994).

Algumas destas dificuldades mobilizam aspectos emocionais do enfermeiro. Segundo Ferreira (1994), as enfermeiras entrevistadas por ela, que cuidam de pacientes com câncer, apresentam as emoções aguçadas ainda mais quando se trata de assistir crianças e adolescentes com câncer.

Nas entrevistas feitas por mim, o fator idade também apareceu como uma das dificuldades que aparecem na lida com o paciente oncológico.

"E o que é mais dificil, às vezes, para mim lidar num paciente oncológico é, às vezes, o fator idade também, eu..., eu tenho muita dificuldade, assim... resolvo, digo tudo bem, mas me deixa mais assim..., abalada quando é jovem, quando ainda é uma mulher que está amamentando e que está com câncer de mama, né?" (Entrevista 1). 
"Eu acredito que existe uma outra, uma outra vida e tudo, mas ainda é muito difícil principalmente com paciente jovem, se for uma paciente jovem, mais adolescente então, adolescente então eu nem me aproximo" (Entrevista 2).

"Os casos mais difíceis que eu já enfrentei eu acho que são algumas adolescentes que nós tratamos no ambulatório de Onco..." e "... porque aí não se inclui só uma vida que ele já passou, mas que ela teria ainda pela frente, né?" (Entrevista 3).

"Não é sempre então que eu falo a verdade para o paciente, assim no sentido do prognóstico dele" $e$ "... eu acho que depende muito por exemplo, é muito difícil conversar sobre isso com uma adolescente que está morrendo, né?" (Entrevista 4).

De acordo com o estudo de Françoso (1993), as dificuldades parecem estar ligadas não só à associação entre o câncer e o sofrimento, complicação e morte, mas à incompatibilidade destes temas com a infância. Segundo as enfermeiras, as dificuldades diante do câncer, de modo geral, são intensificadas quando se trata do câncer infantil.

A infância e a adolescência passam uma imagem de "muita vida pela frente" e saúde, talvez, por isso a pouca idade dos pacientes com câncer "atormente" ainda mais os profissionais de saúde.

Do envolvimento do enfermeiro com o paciente oncológico surgem sentimentos no profissional.

"E... o sentimento que a gente, que eu mais experimento nisso, em paciente oncológico, principalmente é a impotência, tá? Eu acho que é o que mais mexe comigo é a agonia de, de não poder fazer mais nada para poder parar com aquele sofrimento" (Entrevista 1).

"... Raiva da, da coisa da... (pausa), quando não dá para você fazer mais nada, como que é o termo disso? Da impotência, tá?" (Entrevista 2).

De acordo com Françoso (1993) o contato com a morte gera o sentimento de impotência no enfermeiro. Há sofrimento advindo do envolvimento com a criança (paciente oncológico em estudo por essa autora) e a familia e da impotência diante da evolução negativa da doença. Ainda segundo a mesma autora, limitações explicitadas, e a necessidade de lidar com elas de alguma maneira, resultam nas sensações de impotência e de insuficiência (vide entrevistas 1 e 2 imediatamente anteriores). A entrevistada 2 coloca também:

"... eu acho que os sentimentos são esses é pena, é dó, é raiva, é medo até de um dia passar por uma situação dessa, né? É tentar fazer o máximo para assim fazer um tipo de uma troca com Deus, né?" (Entrevista 2). 
Através desse depoimento, nota-se a identificação da enfermeira com o paciente e ao mesmo tempo um mecanismo de defesa (troca com Deus) que ela utiliza para amenizar o medo que ela tem de um dia apresentar câncer. Segundo Menzies (1970), o sistema social de defesa auxilia o indivíduo a fugir da ansiedade, culpa, dúvida e incerteza. No caso da enfermeira, o medo é decorrente da incerteza sobre o seu estado de saúde no futuro. Através dessa "troca com Deus", ela quer se livrar da possibilidade de um dia apresentar câncer.

Como forma de enfrentamento das dificuldades parece que as enfermeiras adotam algumas das técnicas estudadas por Menzies (1970). Uma das técnicas é a de distanciamento. A "independência profissional" pode-se dizer que é outra técnica para conseguir distanciamento, segundo Ferreira (1994).

O enfermeiro usa algumas "estratégias" para lidar com dificuldades e sentimentos até agora citados, que aparecem no seu cotidiano com o paciente oncológico.

"...e você não tem mais o que fazer. $E$ aí seguro na mão, faço um carinho, e fico ali do lado até que... eu também me esgote, (...) e ela também por si vá a óbito ou acabe o plantão e eu tenha que sair de perto..." (Entrevista 1).

Nota-se, através deste depoimento, que situações em que o paciente é terminal, quando o óbito é certo e próximo, a enfermeira se aproxima mais do paciente, ao invés de se afastar como, intuitivamente, era de se supor que ocorresse.

Segundo Françoso (1993), a Oncologia é uma área que lida direta ou indiretamente com questões humanas significativas, ligadas à vida e à morte. $A$ necessidade de afastamento revela-se como saída possivel numa espécie de autopreservação em relação aos incômodos suscitados nesta área. O movimento oposto (aproximação) pode ocorrer. A seguir formas diferentes de lidar com as dificuldades que surgem na lida com o paciente oncológico.

" $E$...quando mexe demais comigo...eu tenho umas manias, né? É eu toco violão, quando a coisa abala demais a estrutura minha naquele dia, ai eu chego na minha casa, eu ando uma hora e meia, duas, toco meu violão, mais uma hora e meia, ou procuro conversar com amigos, soltar isso para fora, falar, falar, chorar e no outro dia estou ótima, revigorada para começar tudo de novo" (Entrevista 1). levantado.

Novamente o tema distanciamento e/ou negação das emoções é

Segundo Ferreira (1994), também parece que ajuda buscar distrações. Exercer alguma atividade física ou executar algum trabalho manual também pode ser uma opção viável. A entrevistada 2 se coloca no lugar do paciente:

"... estar sempre lembrando que essa paciente está passando por um momento muito difícil, eu pelo menos coloco, sabe? na minha cabeça 
o seguinte, eu não gostaria de estar nessa situação, eu não sei como agiria nessa situação..." (Entrevista 2).

Lidar com a dor, o sofrimento e a morte afeta as enfermeiras; no entanto, elas procuram se colocar no lugar do paciente para que assim consigam dar uma boa assistência ao mesmo. Isso também é constatado no estudo colhido por Ferreira (1994).

Menzies (1970) fala de mecanismos de defesa contra a ansiedade utilizados pela equipe de enfermagem em um Hospital Geral de Londres. Segundo Ferreira (1994), o uso de tais mecanismos de defesa seria muito mais intenso se esse estudo realizado por Menzies (1970) tivesse sido feito em serviços de atendimento a pacientes críticos ou com doença crônico-degenerativa que obriga o paciente a longos períodos de internação ou a vários retornos ao hospital. Sem falar daqueles pacientes com doenças ainda consideradas com poucas possibilidades de cura, como o câncer e a AIDS.

O uso de tais mecanismos de defesa contra a ansiedade, citados por Menzies (1970), pode acabar gerando outro tipo de sofrimento para o enfermeiro. Um exemplo é que o enfermeiro, ao fragmentar o seu relacionamento com o paciente, tenta evitar o contato prolongado com o paciente e o possivel sofrimento psíquico oriundo desse contato. No entanto, pode ocorrer que, em decorrência da utilização desse mecanismo de defesa, o profissional acabe privado de uma fonte de prazer do seu trabalho, que é o reconhecimento do trabalho do enfermeiro por parte do paciente. Pois, afinal, são tantos os profissionais de enfermagem que cuidam de um paciente que, de acordo com Menzies (1970), os pacientes ficam gratos ao hospital ou aos "enfermeiros", mas não a ele (enfermeiro "tal") em particular. A ausência de satisfação do enfermeiro aumenta o "stress", que aumenta a ansiedade.

Além disso, o desconhecimento, por parte do profissional, da sua utilização de mecanismos de defesa contra sofrimento psíquico pode por si só acarretar sofrimento para o enfermeiro.

Assim sendo, o enfermeiro, para lidar com o paciente, atendendo suas necessidades físicas e emocionais, sem apresentar um intenso sofrimento psíquico, deveria integrar seus conhecimentos de psicologia e psiquiatria ao cuidado físico dispensado aos pacientes que apresentam problemas clínicos ou cirúrgicos (Kyes \& Hofling, 1985).

Concluindo a idéia acima, um certo conhecimento de psicologia e psiquiatria é necessário ao enfermeiro para atender bem o paciente, praticando uma relação terapêutica como a descrita acima. Esse conhecimento diminuiria também o sofrimento psíquico do enfermeiro que aparece na lida com o paciente oncológico.

Interrogando as enfermeiras em estudo, do CAISM, sobre os requisitos que elas acreditam serem necessários para poder haver uma relação terapêutica com o paciente oncológico, aparecem alguns depoimentos que concordam com o exposto anteriormente e outros acrescentam algumas idéias. 
"Eu acho que o requisito necessário é o equilíbrio psicológico pessoal de cada profissional, tá? É...ele tem que ter o discernimento da dor física, tá?, que um lisador, um injeção pára, mas esse paciente continua chorando? Da dor mental, né? Então eu acho que o requisito principal é este. Você ter conhecimento psicológico, psiquiátrico para que você possa discernir a dor física da mental..." (Entrevista 1).

"Eu acho que um dos requisitos principais que o profissional tem que ter é ... ele próprio se conhecer, tá? A nível realmente psicológico para entender as coisas e poder entender o paciente oncológico, tá?" (Entrevista 2).

"... A nível de cuidados eu, eu acho que...o profissional tem que estar realmente preparado a nível técnico, de conhecimento..." (Entrevista 2).

"Eu acho que o requi..., um dos requisitos necessários e primordial eu acho que é a comunicação, né? Eu acho que a gente ter que parar para ouvir o que ele pensa, o que ele está passando..." (Entrevista 3).

"Eu acredito muito que um bom psicólogo, um bom psiquiatra ajudaria muito, que é o que a gente sente falta lá, na ...na... Unidade a gente não tem isso." (Entrevista 4).

Continuando a questão da relação terapêutica, as enfermeiras em estudo acham-se em condições de estabelecer tal relação com o paciente, umas argumentam e dizem o porquê de acharem isso, contudo outras fazem ressalvas.

"...eu acho que o que faz com que eu continue na Oncologia são os próprios pacientes que a cada elogio que eu recebo faz com que eu continue, né? E graças a Deus eu acho que eu devo estar fazendo isso bem feito, né?, porque os pacientes sentem falta quando eu estou de folga..." (Entrevista 1).

"...mas à nível, à nível psicológico e de relacionamento mesmo humano ainda precisa bastante coisa, tá? Precisa aquela disponibilidade maior durante o meu periodo de trabalho, né?" (Entrevista 2).

"...eu acho que na pior fase da minha vida o retorno maior que eu tive foi, foram das pacientes. A partir da hora que eu passava os meus problemas, (...), é que eu acho que foi a melhor fase para eu estabelecer uma relação tipo um pacto com o paciente, foi bom porque tive muito retorno" (Entrevista 2).

"...no sentido dele estar enxergando, sabendo quem são as pessoas, quem é o enfermeiro, quem é o médico, o que eles estão fazendo aqui, os efeitos sobre a doença, né?, e a tranqüilidade da família de estar junto" (Entrevista 3). 
"Eu acho que sim, porque eu gosto demais tanto de enfermagem quanto da Oncologia, estou acostumada, treinada...então eu não sinto dificuldade e eu acho que eu consigo fazer isso..." (Entrevista 4).

As enfermeiras entrevistadas discorreram sobre os requisitos que elas acreditam serem necessários para poder haver uma relação terapêutica com o paciente oncológico.

No entanto, quando são interrogadas a respeito de se acharem ou näo em condições de estabelecer tal relação com o paciente, elas respondem afirmativamente, contudo as enfermeiras não justificam suas respostas dizendo que possuem aqueles requisitos apontados por elas, anteriormente. Fica então a dúvida de que se elas realmente conseguem cuidar do físico e do psíquico do paciente oncológico.

\section{CONSIDERAÇÕES FINAIS}

Este estudo teve como objetivos identificar as situações enfrentadas pelos enfermeiros de um serviço de Oncologia de um hospital-escola paulista, que mais thes desencadeiam sofrimento psiquico e analisar as formas encontradas por estes profissionais para lidar com tais situações.

Conforme se pôde verificar, as situações que mais causam sofrimento psiquico naqueles enfermeiros estão sintetizadas abaixo e divididas em categorias.

\section{Situaçöes ligadas ao trabalho:}

- A complexidade da assistência: exigência na realização de procedimentos de natureza técnica e envolvimento com o paciente.

- A parte administrativa do trabalho do enfermeiro, muitas vezes, toma o tempo que deveria ser destinado à assistência direta ao paciente.

- O conflito entre a concepção do enfermeiro de atitude profissional ética e fatos ocorridos em um hospital-escola.

- A falta de preparo (do enfermeiro) específico na Área de Oncologia.

\section{Situaçōes ligadas ao tipo de paciente:}

- As dificuldades físicas para lidar com o paciente, pois este, muitas vezes, fica acamado e há falta de recursos hospitalares a nivel de Brasil.

- O fator idade: quanto mais jovem o paciente, mais dificil para o enfermeiro é a lida.

\section{Situações ligadas ao tipo de doença:}

- A falta de preparo do enfermeiro para lidar com a morte.

-O câncer é, na maioria das vezes, uma doença de mau prognóstico.

Os ítens abaixo podem estar relacionados, ao mesmo tempo, com os três fatores já citados: trabalho, tipo de paciente e tipo de doença: 
-O sentimento de impotência do enfermeiro perante a situação do paciente oncológico.

-A identificação do enfermeiro com o paciente.

-O uso inadequado, pelo enfermeiro, de mecanismos de defesa contra sofrimento psíquico.

-O desconhecimento, por parte do enfermeiro, da sua utilização de mecanismos de defesa contra sofrimento psiquico.

As formas encontradas, pelos enfermeiros, para lidar com situações que thes acarretam sofrimento estão colocadas abaixo:

-O uso de um mecanismo de defesa, a negação, não falando de sofrimento e de morte como se não existissem. Outro meio de o enfermeiro negar tais situações é através da sua ocupação com um grande número de funções para não haver tempo de pensar na gravidade do câncer (este último exemplo também pode ser um mecanismo de sublimação).

- O enfermeiro pode recorrer à sublimação buscando distrações, fazendo atividades fisicas ou executando um trabalho manual.

- O enfermeiro pode se afastar ou se aproximar ainda mais do paciente. Este é um mecanismo de identificação.

- O uso de um mecanismo de defesa, onde é feita uma barganha com Deus: o enfermeiro faz o que pode pela saúde do paciente em troca da sua própria saúde.

- A "independência profissional" (Ferreira,1994) do enfermeiro: não misturar problemas do trabalho com a sua vida pessoal.

- O enfermeiro pode usar a compensação como mecanismo de defesa, e então passa a fazer o "máximo" pelo paciente.

- A aplicação de recursos psicológicos e psiquiátricos a situações cotidianas que causam sofrimento psíquico.

Este trabalho é importante por ser ainda pequeno o número de estudos que envolvem a questão do relacionamento do enfermeiro com o paciente que tem câncer.

Mostrando vários pontos de sofrimento psíquico do enfermeiro e algumas maneiras utilizadas por ele para lidar com tal sofrimento, deseja-se contribuir para que pessoas da coordenação e gerenciamento do pessoal de enfermagem possam adotar meios para atenuar tais problemas.

Apenas como sugestão, poderiam ser feitas reuniões com auxilio de profissionais capacitados (enfermeiros ligados à Saúde Mental, psicólogos e psiquiatras), onde o enfermeiro da Área de Oncologia pudesse falar sobre suas dificuldades na lida com o paciente e receber suporte para trabalhar com estes problemas.

Com este estudo, espera-se poder contribuir para a compreensão do desafio que é o câncer, doença que amedronta profissionais e a população em geral. 


\section{ANEXO \\ ROTEIRO DE ENTREVISTA}

1. Como você descreveria o seu dia-a-dia com os pacientes que têm câncer?

2. Como você acredita que os pacientes devem ser tratados?

3. Quais os casos mais dificeis que você já $\epsilon$.ffrentou?

4. O que você faz nestas situaçōes?

5. Quais as dificuldades que você identifica para lidar com paciente oncológico e como você faz para lidar com elas? Quais os sentimentos que você mais experimenta?

6. Você já cuidou de um paciente com câncer em estágio terminal? Se sim, como foi esta relação?

7. Quais os requisitos que você acredita serem necessários para poder haver uma relaçäo terapêutica com o paciente oncológico?

8. Você se acha em condições de estabelecer uma relação terapêutica com o paciente?

9. Quando você recebe a notícia de que um conhecido seu está com câncer, qual a primeira coisa que passa pela sua cabeça? Ou ainda, câncer para você tem algum sinônimo que possa traduzir o que você pensa sobre a doença?

10. O que o levou a trabalhar no Setor de Oncologia?

\section{REFERÊNCIAS BIBLIOGRÁFICAS}

1. BARDIN, Laurence. Análise do Conteúdo. Lisboa: Edições 70, 1979.

2. CASSORLA, Rooselvet M. S. Aspectos psicológicos da relação médicopaciente com câncer. Estudos de psicologia, n.1,p.48-62, 1983.

3. COFEN. Código de ética dos Profissionais de Enfermagem. São Paulo: COFEN, 1993.

4. D'ANDREA, Flávio Fortes. Desenvolvimento da personalidade: enfoque psicodinâmico. Rio de Janeiro: Bertrand Brasil,1996.

5. DEJOURS, C. A loucura do trabalho: Estudo da psicopatologia do trabalho. São Paulo: Cortez-Oboré, 1992. 168p. 
6. FAZENDA, I. C. A. Interdisciplinaridade: história, teoria e pesquisa. Campinas: Papirus, 1994.

7. FERREIRA, Noeli Marchioro Liston Andrade. A difícil convivência com o câncer. um estudo de emoções na enfermagem oncológica. São Paulo, 1994. 133p. Dissertação (Mestrado. Pontificia Universidade Católica de Săo Paulo).

8. FRANÇOSO, Luciana P. Castilho. Enfermagem: Imagens e significados do câncer infantil. Ribeirão Preto, 1993. Dissertação (Mestrado. Universidade de São Paulo).

9. GERMANO, Raimunda M. A ética e o ensino de ética na enfermagem do Brasil. São Paulo: Cortez, 1993.

10. IRVING, Susan. Enfermagem psiquiátrica básica. Rio de Janeiro: Interamericana, 1978.

11. KYES, Joan J., HOFLING, Charles K. Conceitos básicos em Enfermagem psiquiátrica. Rio de Janeiro: Guanabara, 1985. 551p.

12. LUDKE, Menga, ANDRÉ, Marli. Pesquisa em educação: Abordagens qualitativas. São Paulo: EPU, 1986.

13. MENZIES, I. E. P. O funcionamento das organizaçōes como sistemas sociais de defesa contra a ansiedade. São Paulo: 1970. 56p. (Artigo mimeografado traduzido por Aracky M. Rodrigues).

14. MINAYO, Maria Cecília de S. O desafio do conhecimento: Pesquisa qualitativa em saúde. 3ed. Rio de Janeiro: HUCITEC-ABRASCO, 1994.

PITTA, Ana. Hospital: Dor e morte como oficio. São Paulo: Hucitec, 1994.

15. SILVA, Graciette Borges da. A enfermagem profissional: Análise critica. São Paulo: Cortez, 1986.

16. THIOLLENT, Michel. Crítica metodológica, investigação social e enquete operária._São Paulo: Polis, 1980. 213p. 